\title{
Clues to the origin of the human mind from primate observational field data
}

\author{
RICHARD W BYRNE ${ }^{1}$ \\ School of Psychology, University of St Andrews
}

\begin{abstract}
Field study of wild animals is often asserted to have no role in discovering the cognitive capacities of the animal mind. In this lecture, I challenge that view, giving two examples where field data have revealed unsuspected cognitive capacities and allowed theoretical advance in understanding the evolutionary origins of human cognitive capacities. In the first, narrative records of deception of social companions were used as an 'index' of species' capacity for subtle social manipulation. This capacity was found to be widespread among primates, and to depend on neocortex volume, thus supporting theories that implicate social complexity in increasing primate intelligence. Intentional deception follows a quite different pattern, being rare and clumped in the great apes. The origins of the ability to understand others' behaviour, in terms of their intended purposes and the cause-and-effect involved in achieving them, forms the topic of my second example, great ape food processing. Wild apes regularly develop computationally complex organizations of behaviour, neatly adapted to solving food-acquisition problems and thus acquiring foods unreachable by sympatric competitor monkeys. Converging analyses of these manual techniques point to the underlying ability of 'parsing behaviour', giving apes (but perhaps no other animals) the ability to understand behaviour in a simple way, in which satisfying results stand for 'goals' and regular prior correlates stand for 'causes'. In both cases, there are obvious implications for human cognitive evolution.
\end{abstract}

The conventional wisdom in animal psychology is that field-study of a species in its natural environment has an important but limited role. Its role is that of discovering the natural form and biological function of behaviour; but field-study has no useful part to play in discovering the cognitive basis of behaviour. If psychologists wish to discover the cognitive processes involved in animal behaviour they must use laboratory experiments.

In this paper I would like to challenge that tidy division. Laboratory experiments are

1 Scottish Primate Research Group and Centre for Social Learning and Cognitive Evolution, School of Psychology, University of St Andrews, St Andrews, Fife KY16 8PL, Scotland

Published online in J-STAGE: June 8, 2007 doi: $10.2502 /$ janip.57.1.3 certainly invaluable to investigate behaviour that never occurs under natural conditions, and they are useful for increasing the frequency of behaviours that would rarely be observed in the field so that they can be examined under close scrutiny in a managed environment. Laboratory experiments also allow great convenience and efficiency, for example when collecting controlled data, matching sample sizes and so forth. But I propose that cognition can also be studied in the wild, and that there are real benefits from doing so. These benefits are complimentary to laboratory work and may allow us to make unique deductions about the cognitive basis of animal behaviour. In particular, data from primate field observation can contribute to one of the 'big issues' of psychology: that is, understanding the origins of human cognition. 
It is of course widely accepted that many human cognitive abilities are matched by corresponding animal behaviours, but there are certain attributes of human cognition that seem very special. I would draw attention particularly to the ability to understand what others are thinking, sometimes called mentalising, to the use of structure in making and building things, which we call technology, and to the use of structure in vocal communication - structure as syntax. Understanding the evolutionary origin of these abilities is something of a 'Holy Grail' for human cognitive evolution: where they came from is one of the great mysteries of psychology. This paper will use as illustration two studies of primate behaviour, one concerning social intelligence and one concerning technical intelligence, in order to argue that observational field data can help us gain some clues to the origins of these 'Holy Grail' abilities.

\section{Social Complexity, Brain Size, and Intentionality}

The idea of 'Machiavellian intelligence' that is, that the cognitive challenge of dealing with other individuals in a long-lasting social group was a major stimulus to the evolution of intelligence - originated in several places. Alison Jolly pointed out that the lemurs she was studying were highly social but they seemed to lack intelligence, so the common idea that intelligence was a prerequisite for the formation of complex society didn't seem right (Jolly, 1966). She suggested instead that it might work the other way round: sociality leading to intelligence. Nicholas Humphrey took the idea much further in a seminal paper in 1976, arguing that the major challenge confronted by any social animal was significantly more severe than the environmental or technical challenges they faced, and was likely to be the main stimulus to the development of primate intelligence (Humphrey, 1976). Andy Whiten and I, in a book that introduced the term 'Machiavellian intelligence' in 1988, brought these ideas together and assembled data suggesting they might be right (Byrne \& Whiten, 1988). A few years later, Lesley Brothers suggested that one could trace these adaptations by looking at the brain itself (Brothers, 1990). Robin Dunbar, in a series of papers, has shown that investment in the neocortex of the brain correlates with measures of social complexity, for example group size or grooming clique size, but not with measures of environmental complexity, for example day journey length, home range area or the use of embedded foods (Dunbar, 1998). This relationship has been found to hold not only for primates but also for bats, carnivores, cetaceans and ungulates.

There is, therefore, substantial support for the idea that social complexity has been a major driver of the evolution of enlarged brains and greater intelligence in animals. But the measures are generally indirect ones: they don't concern the actual social manipulation that is supposed to be the whole point of a larger brain for living in a larger group. So data is also needed to show whether a larger neocortex really pays off, in terms of social skill, and here is where data from the field can help out.

In the 1980 s it was thought that deception within the social group was restricted to chimpanzees, but my colleague, Andy Whiten, and I showed that this was incorrect. We assembled a large corpus of records of tactical deception, contributed by field workers all over the world, and found that deception was a scarce but routine aspect of natural primate behaviour (Byrne \& Whiten, 1990). The behaviours were often subtle, but I should stress that, by the term 'tactical deception', we did not imply that the animals themselves understood the mechanism of deception: only that their behaviour functioned by causing other individuals to be deceived, and therefore manipulated to the agent's advantage. The records of deception that we assembled were spread widely over the primate order (Figure 1), but their distribution was by no means uniform. Cercopithecine monkeys and the common chimpanzee, for instance, seemed to use deception more than average. Of course, large bodied Old World Monkeys and chimpanzees have also been more heavily studied than most primates: it is therefore important to examine these records in the context of observer effort. But even when we corrected for observer effort, 


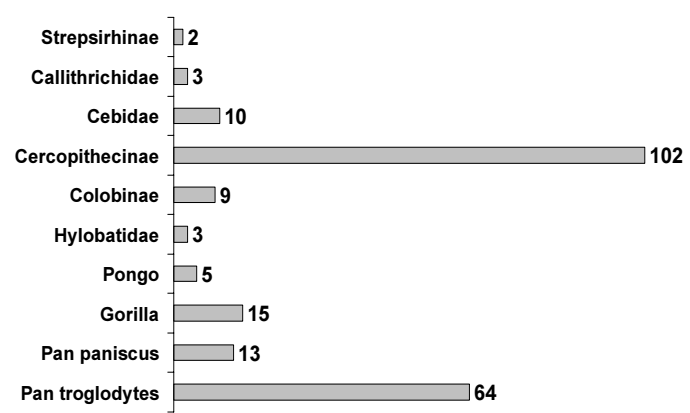

Figure 1. Tactical deception in primates. Frequency of records according to primate taxa, uncorrected for variation in observer-effort.

there were still real differences among taxa of primates (Byrne \& Whiten, 1992). Could it be, therefore, that these differences corresponded in some way to the intelligence of the species?

Nadia Corp and I used these data on frequencies of tactical deception as an index of social skill, in order to compare it with measures of brain enlargement (Byrne \& Corp, 2004). We corrected the tactical deception data for effort, and used the method of independent contrasts to remove phylogenetic effects. Then, we examined the correlations of tactical deception with the volume of the neocortex, the volume of the rest of the brain, and the size of the social group. The reason for including group size was because of the possibility that we might otherwise pick up a correlate of group size as an artefact. On the one hand, it might be

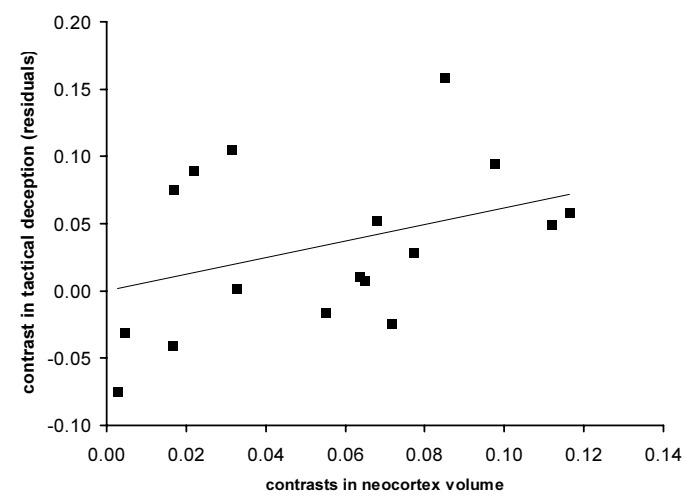

Figure 2. Neocortex size predicts the use of tactical deception. Correlation between contrasts in neocortex size and contrasts in deception frequency, after correction for observer effort. that larger groups give more opportunities for the animals to show their abilities; on the other, it might be that primatologists would be more likely to record deception in larger groups, simply because there was more behaviour going on. However, in fact social group size failed to produce any significant effect, even when forced first into a multiple regression. The same applied to the variable, rest-of-brain size. The only significant correlation was with neocortex volume (Figure 2). Increased neocortex size really does allow primates the luxury of increased use of social manipulation by deception, and presumably by other subtle tactics.

I have stressed that these records of deception were not collected in any belief that the deception was carried out intentionally with malice aforethought and with an understanding of mechanism. But the possibility needs to be considered. Interpretation can often be ambiguous (Figure 3). Many years ago, Hans Kummer described the surreptitious behaviour of a female Hamadryas baboon, shifting herself very slowly over a period of 20 minutes to a position where she could groom a subordinate male, without her harem leader being able to see what she was doing (Kummer, 1968). The harem leader could see that she was present, but not what she was doing with her hands, or detect the presence of the other male who would normally be forbidden to interact with her. As Figure 3 shows, this set of data can be ascribed to three separate possibilities. In the most richly intentional, the female is thinking about her harem leader's thoughts - that he is thinking something that is false, i.e. behind the rock there is no other baboon. A less intentional version has the female thinking about her harem leader's view - that while he can see her, he can see nothing other than the fact that she is present. And finally, in the least intentional, the female baboon is merely thinking about her harem leader's position - that from the position where he is sitting there is nothing revealing to be seen, no mental states of any kind are involved. So the same data may reflect an understanding of false belief, of seeing, or only of everyday geometry. 
(a)

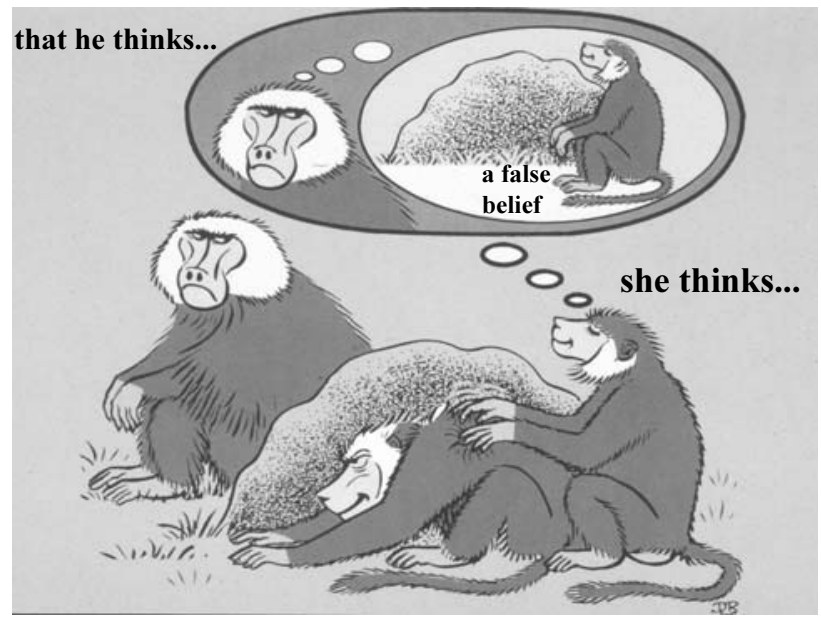

(b)

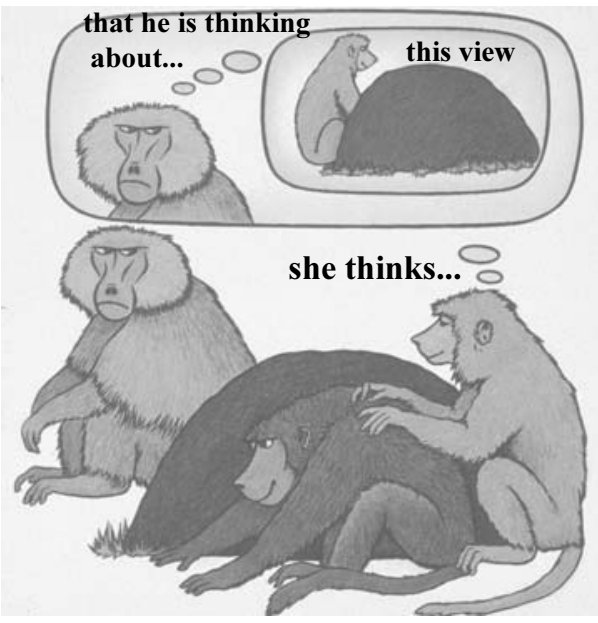

(c)
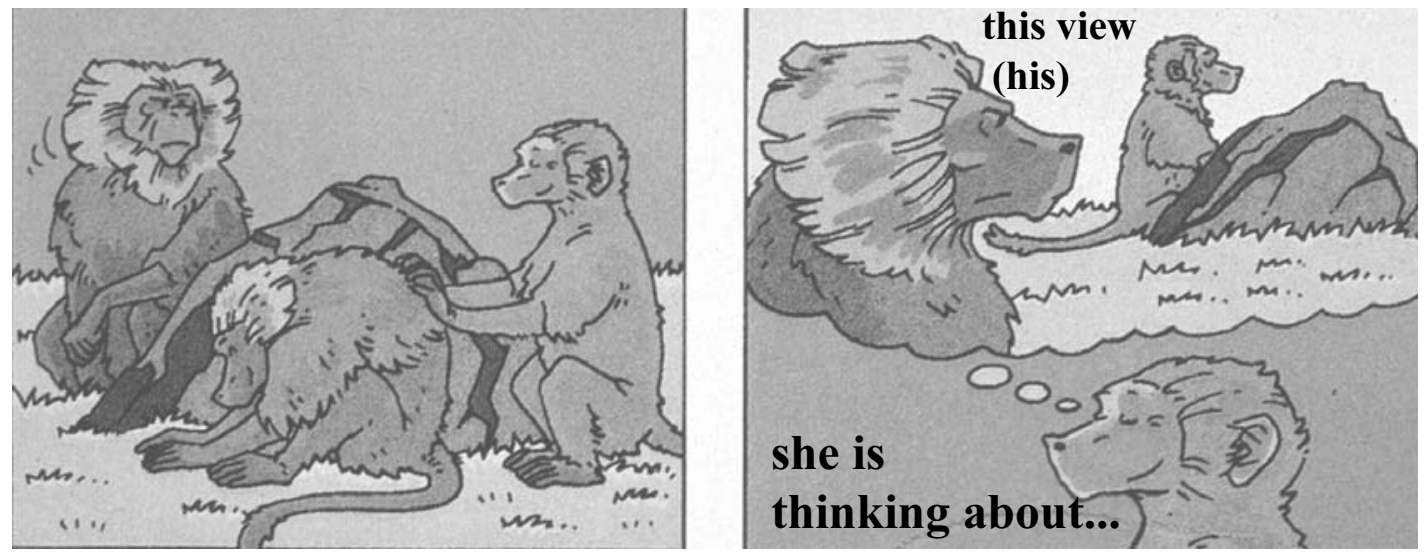

Figure 3. Interpretations of the same case of deception. All three cartoon depictions refer to the same case, a female hamadryas baboon who misled her harem leader about her interaction with another male.

This gave us a problem. Could we find out the level of intentionality of narrative deception records, to find out whether our initial scepticism was warranted or whether perhaps some animals really did understand or plan their deceptions? We took the approach of Ockham's Razor, assuming that if we could reasonably explain the behaviour in a simple way we should do so. We took the 'simplest' explanation to be that the trait was hardwired in the genes of the individual. The next simplest explanation would be that the animal had learnt the deception on the basis of previous experience but without really understanding it. The most unlikely possibility, of course, was that the animal really understood what it was doing.

We examined the hundreds of records, evaluating each for the plausibility of accounting for it in as simple a way as possible (Figure 4). The result was surprising. The great majority of records could be explained by one of the two 'killjoy' hypotheses, hardwiring or learning, quite plausibly. However, we independently agreed that none of a small group (about 20) records could not be explained in either way without gross implausibility. The issue remains one of judgement, but I think it is significant that these records all clustered in a single taxon of primates, the great apes. So we asserted in 1992 that these observational data 


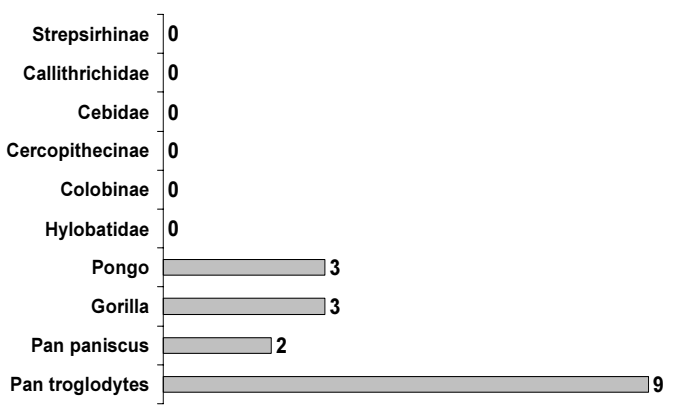

Figure 4. Intentional tactical deception. Most records can be plausibly accounted for without attributing any great understanding to the primate agents; these cannot.

gave evidence that great apes have some capacity to take account of the knowledge and beliefs of other individuals (Byrne, 1995; Byrne \& Whiten, 1992). Ten years later, this evaluation finally received support from the captive experimental literature (Hare, Call, Agnetta, \& Tomasello, 2000; Hare, Call, \& Tomasello, 2001). If the observational field data had been taken more seriously a decade earlier, we could have saved ten years of somewhat acrimonious argument between field workers and laboratory researchers, and the current rapprochement between data from laboratory and field could have come in the early 1990s.

These data from the natural lives of primates in the field can be interpreted to give us some insight into the evolution of human abilities. First of all, the general prevalence of deception in at least the simian primates can be seen as a result of an ability to learn very quickly in social contexts - that is, to pay attention to other individuals and their demeanour, to acquire and use knowledge about rank and relatedness and individual histories; to learn tactics that pay off from coincidental opportunities presented in the natural way of things. These abilities, associated with the considerable enlargement of the neocortex of the brain, were present at least in the ancestor of all modern simian primates (Figure 5) at least 30 million years ago. Then, specifically in one branch of this radiation, the ancestral great apes of around 12 million years ago, the ability developed to take account in

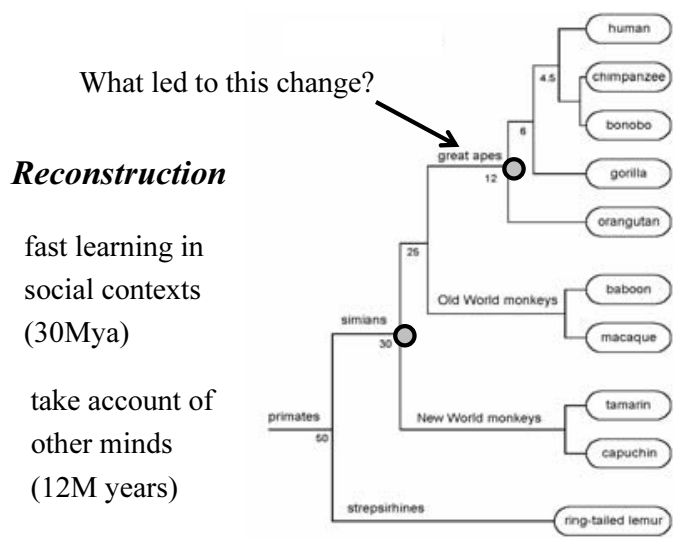

Figure 5. A possible evolutionary reconstruction. The two bold points on the cladogram indicate (1) the development, at least by $30 \mathrm{Mya}$, of the ability to show fast learning in social contexts and appropriately enlarged neocortex, in the ancestral simian primate; and (2) the development, at least by 12 Mya, of the ability to take account of other minds in some way, in the ancestral great ape.

some way of other minds and the knowledge and beliefs of other individuals. What might have led to that second development? In examining this question, I shall again use field data, but this time from the context of feeding.

\section{Foraging skill, Imitation and Behaviour Parsing}

We have seen evidence that the intellectual challenges presented by increasing group size led to the initial enlargement and greater learning potential of primates. Might the same pressure have led also to more sophisticated social cognition in great apes? Apparently not: the great apes live in groups that are no larger than monkey species, Remember that group size is the key proxy variable for social complexity. Chimpanzees live in groups comparable to those of baboons; gorilla group size is in the typical range of those for Old and New World monkeys, and smaller than many; orangutans are essentially solitary. If social complexity cannot be argued to be the challenge that might have resulted in this special ability of great apes, what could have been?

Great apes differ sharply from the Old World monkeys in several ways, all to do with feeding. Firstly, great apes suffer higher loco- 
motion costs than monkeys, by virtue both of their much greater size and also from the mechanical inefficiency of travel on the ground by knuckle walking or fist walking, in species adapted to brachiation. Also, despite their larger size, great apes are unable to digest fruit as unripe, or leaves as tough or mature, as can be exploited by their Old World monkey competitors. And the monkeys compete directly with apes for almost all the same foods, and live in almost all the habitats of modern apes. It might seem that the odds are stacked against great apes, in feeding competition with monkeys, that they should already be extinct! (And indeed many Miocene apes did become extinct.) This implies that the ancestors of modern apes must have had some compelling competitive advantage over monkeys, or they would indeed have been forced into extinction. I suggest that this advantage might be the more efficient acquisition of feeding skills.

How might great apes acquire the skills they need in foraging? Certainly not by teaching, which has virtually never been observed in primates (Caro \& Hauser, 1992). In a study aimed at understanding the acquisition of stone tool use in chimpanzees, Boesch recorded only two cases of active teaching in eleven years of observation (Boesch, 1991), and no further record has been added in the years since that study was published. Nor is there any obvious use of 'looking hard specifically to learn'. It is true that young great apes do look at their mothers when processing food they cannot get themselves, but largely in the context where the mother would be prepared to share: for example, the nuts cracked at a stone tool using site. The methods of acquisition do not seem to be what the youngsters are looking at. Nadia Corp and I showed that infant chimpanzees stare intently at Saba florida fruit processing by the mother, but mainly at a time when sharing is most likely and not at all at the earlier stage, when they would have little knowledge of the difficult feeding process involved in obtaining the food (Corp \& Byrne, 2002).

What about imitation? Well most animals apparently simply cannot learn new things by imitation (Galef, 1988; Visalberghi \& Fragaszy,
1990). The published literature that has repeatedly claimed imitation in a range of primates and other non-human animals (e.g. Galef, Manzig, \& Field, 1986; Voelkl \& Huber, 2000; Whiten, Custance, Gomez, Teixidor \& Bard, 1996; Zentall, 2001), can be more simply explained as a consequence of priming: that is, observational facilitation of a tendency to make an action that is already in the animal's repertoire, so nothing new is being learnt except possibly the context of use (Byrne, 1994, 1998, 2002). Those data all come from laboratory studies; perhaps fieldwork can do better and find clear evidence of imitation?

Learning a new skill requires a number of practised actions, each already in the repertoire, to be organised together in a new way; this process may be affected by several things. Firstly, the physical possibilities of the environment may act as channels or constraints to encourage behaviour in particular directions. Secondly, novelty may be internally generated in a process that in humans we would call planning, when ideas and motor possibilities are put together in advance of use simply by the mind's operation. And thirdly, most relevant here, seeing conspecifics exhibit the skill may affect the process of learning, in which case we would call it social learning. Social learning itself can be of two different kinds, depending on how the animal 'sees' the behaviour. If the behaviour is perceived wholly in terms of the places where a conspecific goes and the objects that it uses, then we would expect social learning to be a matter of stimulus or local enhancement. Stimulus enhancement causes an increased tendency to go to certain places and to interact with certain objects in the stimulus array, and the narrowing of explorative focus may result in more rapid learning. On the other hand, if the observer has the ability to see behaviour in terms of actions and how they are organised, then it will also have the possibility of imitation (Byrne, 2003). Imitation of that kind is likely to be most valuable where the task is relatively complex and the solution relatively counter-intuitive.

An example of such a task is the feeding on nettles, Laportea, by the mountain gorillas of 
RICHARD W BYRNE : Clues to the origin of the human mind from primate observational field data

Rwanda. This species of nettle is high in protein and low in structural carbohydrates and lignin; it is therefore a highly advantageous food for gorillas; but, like the nettles that are familiar to those of us who live in temperate regions of the world, nettle eating presents a

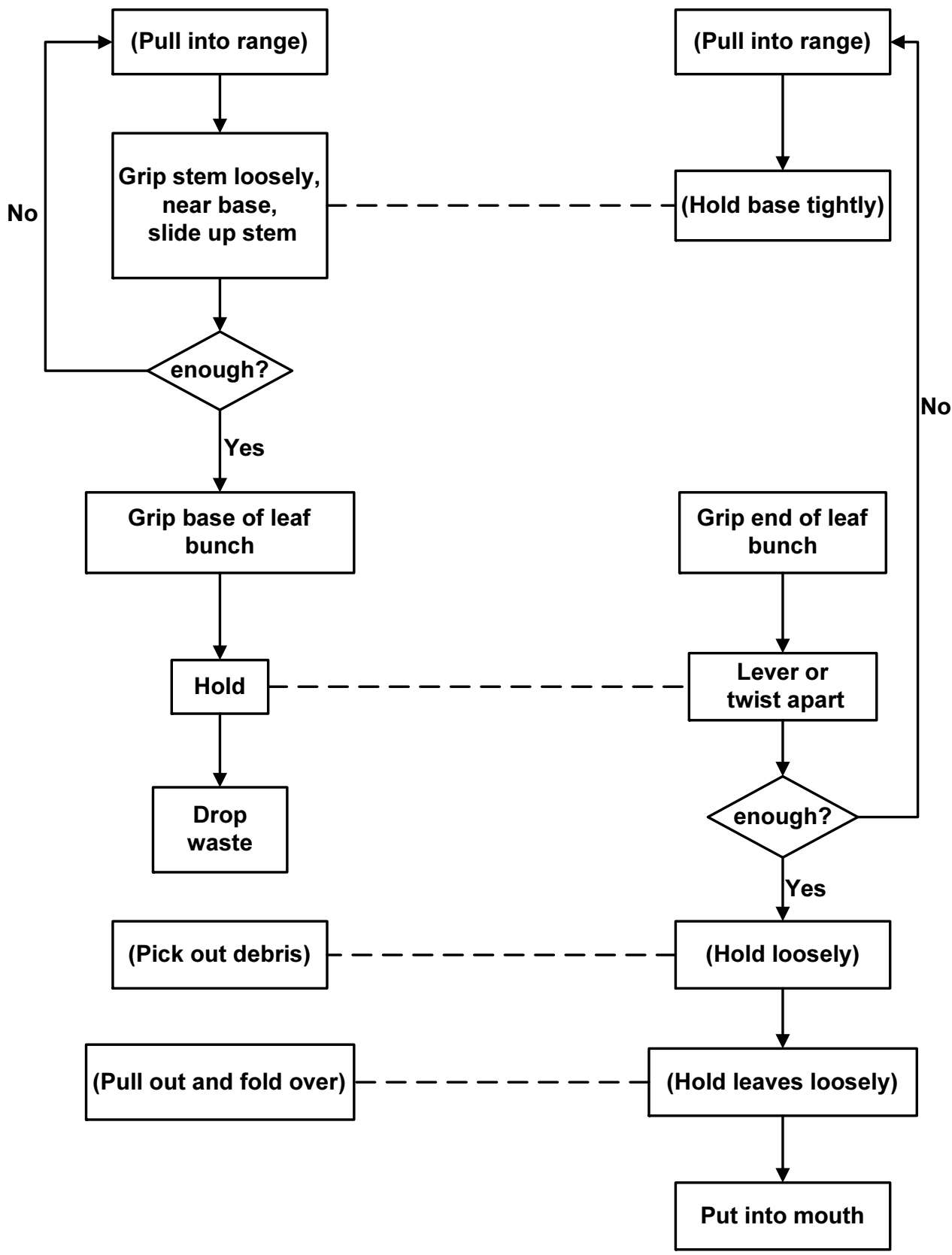

Figure 6. Flow chart of the actions undertaken by a mountain gorilla while eating nettle leaves. The process begins at the top of the figure, with actions of the left hand shown in the left column and vice versa. Diamonds represent choice points, dotted lines show bimanual asymmetric coordination between the hands, brackets mark actions that are omitted if not needed in a particular case. 
major problem, in that the plant is covered in painful stinging hairs that are triggered by contact. These hairs are most abundant on the stem and the leaf petioles; they are also found around the edges of the leaf and on its upper side, but least on the leaf's underside. Dealing with nettles, and obtaining a large number of leaf blades with the minimum amount of pain and trouble, is a significant technical problem for a young gorilla to learn. The solution it will most likely develop is not an intuitively obvious one. If one asks people who are thoroughly familiar with nettle and well aware of its distribution of stinging hairs to devise a suitable approach, they typically think of picking the leaves one by one by holding the upper part of the petiole, accumulating them in the other hand, then eating the pile with mouth wide open. Gorillas do better than this (Figure 6). The plant is first pulled into range by holding the upper leaves on the stem, new leaves on which the stings have not fully developed (Byrne \& Byrne, 1993). Then the stem is loosely gripped near its base with the hand in an open cone shape, and the hand slid up the stem and the leaves detached. If necessary, the plant is held with the other hand at the base to stop it pulling out of the ground. The result is that several whorls of leaves are detached, but only the leaf underside touches the delicate skin between thumb and palm. Then the bunch of leaves is gripped firmly while the other hand takes hold of the leaf petioles: working together, the two hands then twist or lever the petioles apart from the blades, and the petioles are then dropped as waste. Now the bundle of leaf blades is in the opposite hand to that which stripped them off the stem, and if there is any debris in the bundle it is held loosely, allowing debris be picked out by delicate actions of the other hand. Finally, in order to tuck the sting-infested edges of the leaves firmly inside the underneath of a single leaf, the hand is loosened slightly and the other used to pull out and fold over the top of the bundle, which can then be neatly popped into the mouth. The flowchart reveals that parts of this process can be repeated several times in order to accumulate a larger bundle of leaves, if insufficient are acquired from a single plant for efficient processing. Either the first two stages or the first five stages of the process can be repeated in this way. Certain processes are optional, missed out if there is no real need for them. But the most striking feature is the bimanual coordination between the left and the right hand performing different actions but with a single purpose in mind (Byrne, Corp, \& Byrne, 2001a); for example, the right hand might grip plant material and twist clockwise, while the left hand turns in the opposite rotation, in order to tear apart the material.

Similar levels of complexity are found in the different processes used to deal with the other major food plants of the mountain gorillas. In the case of thistles, leaves and stems are eaten in such a way that the hard woody spines found on leaf edges and the flanges of the stem are processed to face outwards rather than sticking in the throat when the leaves are consumed. With bedstraw the problem is rather different; bedstraw is a clambering plant covered with tiny hooks, whose function for the plant is not one of deterring eating, but rather to hang on to other vegetation. Nevertheless, eating stems of bedstraw is liable to cause choking when the little hooks catch in the throat. The way that gorillas deal with this is to pick out a number of stems, concertina them together to form a tight bundle, which is then eaten with shearing actions of the molar teeth; effectively crushing the hooks together into a mass of vegetation so they no longer have any function.

We have shown that the gorillas processes for dealing with these plant tasks is complex in a number of ways (Byrne, Corp, \& Byrne, 2001b). The repertoire of actions is very large: for example for thistle processing we counted 222 actions, but of those only about 46 were functionally distinct in that they had different effects on the plant material. This still seems to be very much greater than that employed in most primate feeding skills (but see Boesch \& Boesch, 1983, 1993). Moreover, there was a consistent sequence of independent stages in the process: for both nettle and thistle processing the minimum sequence length was five stages. This is comparable to the number of 
stages involved in chimpanzee tool-using tasks (Goodall, 1986), although it is rather short compared to many everyday human activities. Intriguingly the gorilla behaviours were highly lateralised; for thistle 21 out of 33 subjects were either $100 \%$ or $0 \%$ right handed, and for all the tasks the great majority of the subjects were significantly lateralised (Byrne \& Byrne, 1991). For several of the tasks there was also a significant trend towards population righthandedness: for example, for thistle, $64 \%$ of individuals performed the processing in such a way that their right hand was used for fine finger manipulation. The degree of lateralisation and the extent of the trend towards right-handedness suggests that these tasks are really testing ones for the animals, because in humans we know that it is when tackling the challenge of delicate manipulative tool using tasks like writing that we show up as being most lateralised and most right-handed.

In all the tasks involving tricky feeding problems, coordination is critical to the complexity. Firstly, each technique has several stages of bimanual, asymmetric processing in which the two hands are used independently in different activities but to a common end. Secondly, coordination is used also within a single hand, and digits or groups of digits can evidently be used independently. We see this particularly when plant material is accumulated, by manoeuvring the material already held in the thumb and first fingers further back in the hand, so that thumb and first fingers can continue the processing, gradually adding to the bundle.

Having described the general characteristics of these tasks, we can ask whether imitation has a role in their acquisition. If we look at the structural organisation of each task - for example, the sequence of actions, the structure of modules or sub-routines, coordination between and within the hands - we can see that these tasks are apparently complex and not intuitive. Yet the techniques are highly consistent. If on Monday a particular gorilla carries out a task in one way, we can be sure that it will do it virtually the same on Tuesday, next week, and indeed next decade. Moreover the tasks are standardised across every individual in the whole local population. It is true that roughly half will perform the actions in a left-handed form and the other half will perform them in the right-handed form but apart from this mirror image difference the tasks are carried out essentially the same way by everyone. The technique shown in figure 6 , or its reflection, is the same in virtually every individual. So, if each animal in the local population manages to learn just the same highly complex method, it strongly points to the use of imitation - but how can we increase confidence in this suspicion?

There are several lines of evidence that argue that this interpretation is correct. One comes from the study of disability. In many populations of great apes in Africa, great apes sadly encounter snares set for other species of animal. Adults tend to avoid these dangers but the inquisitive young infants can be very badly maimed by a snare going off in their hands (Stokes, Quiatt, \& Reynolds, 1999), and in some populations, for example the chimpanzees of Budongo in Uganda, as many as $25 \%$ of the population may be disabled in this way. Of course many other apes will have died from their wounds, but how do chimpanzees and gorillas ever survive having their hands seriously maimed, when they are reliant on skilled, dextrous manual foraging? Emma Stokes investigated this in the population of chimpanzees at Budongo (Byrne \& Stokes, 2002; Stokes \& Byrne, 2001).

There are two classes of explanations for how disabled young apes might acquire their techniques. On the one hand, the view from traditional comparative psychology would be that any complex processing of this kind is acquired by individual learning (Tomasello \& Call, 1997): by trial and error exploration, shaped by the nature of the ape hand and the affordances presented by the plants themselves. If this were the case, we should expect novel techniques in the maimed animals since their hands have entirely different capabilities and affordances. On the other hand, if the supposition that imitation is involved is correct, then the only model to imitate available to a young 
great ape is the mother (African great ape females are remarkably solitary when feeding). It is most unlikely that the mother would herself happen to be an injured individual, and even more improbable that she should suffer from exactly the same damage as her infant. So, in general, young disabled apes must copy the behaviour of able-bodied adult. They should therefore turn out to have the same technique as the able-bodied, modified only in details to enable it to be performed with the disablement of the hand. Stokes' work showed clearly that the latter was the case. Even severely disabled chimpanzees nevertheless use the same overall technique as able-bodied individuals; they therefore modify their actions at a number of places, but the modifications are a matter of details, at the level of description where we find normally find variation and idiosyncrasy in the population.

Does this mean that African great apes have an understanding of the cause-effect relations and the intentions behind the behaviour that they are imitating? We think not (Byrne, 1999; Byrne, 2003). The underlying structure of a task can be revealed in a number of ways that are perhaps best described as statistical regularities. For example, it is a commonplace of psychology that every time we execute a motor action it will be done slightly differently; but clearly some aspects must be more or less constant or the object of the action will not be reached. The extent of invariance will therefore differ at different points in a sequence of motor processing: at certain points variation must be minimal or absent, otherwise the task could not be done, whereas at others considerable variation may be possible without ill effect. If an observer, of a task carried out a number of times by a skilled practitioner, can as it were 'statistically average' their views, then the points of minimal variance can be identified. These points of minimal variance will, of course, highlight key stages of the overall process; for example, in the case of processing nettle, the stages of detaching petioles, folding leaf blades, removing debris, and popping through the lips will be the steps with least variance. As psychologists, "looking in from the outside', we might label these as the sub-goals of the process - but the point is that these sub-goals can be identified, in the right order, simply by statistical averaging (Byrne, 2003). In a similarly statistical way, information on modularity can be obtained by noting the distribution of pauses (pauses are more likely to occur between modules than within them), noticing the optional omission of parts of the sequence (which automatically parses the remaining sequence), and from the smooth recovery from interruptions. Apes, for example, may be distracted in the middle of feeding by other, social behaviours; if an interruption occurs between modules then we can expect them to retrieve their place in the process, without having to start again at the beginning. Information on the use of sub-routines is 'visible' because of the option of repeating action sequences. Also, alternative methods may be substituted, for example, when a feeding technique is employed, unusually, while the animal is arboreal, so that only one hand is available for something that more conveniently would be done with two, an alternative method has to be used. Such substitutions reveal the organisation. In short, numerous clues are available to an observer of repeated skilled attempts at the same goal. It was by using exactly these kinds of evidence that we, as researchers, were able to discern the hierarchical organisation of the gorillas' food processing tasks (Figure 7). If researchers can do it on the

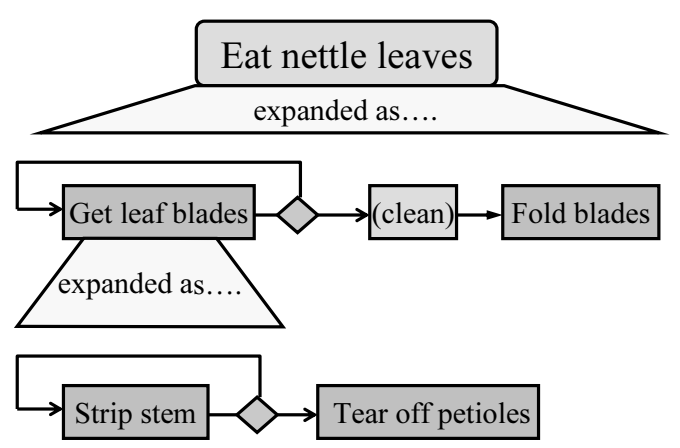

Figure 7. Hierarchical organization of nettle processing. This diagram shows the minimal extent of hierarchical organization of the process that governs nettle processing (see figure 6). 
RICHARD W BYRNE : Clues to the origin of the human mind from primate observational field data

basis of visible cues, then so can the animals themselves.

\section{Implications for human psychology and cognitive evolution}

This leads us to a very different view of imitation than that common in developmental psychology. For example, Tomasello, Kruger and Ratner (1993) note that to imitate, "the child must imaginatively place herself in the circumstances of the adult to determine what is the purpose of the behaviour and how one goes about accomplishing that purpose". Some accounts propose even deeper levels of intentional understanding are involved in imitation, for instance, "imitative copying ... may involve second order representation, insofar as the acts done by (and perhaps the intentions of) the model have to be translated from what is involved in doing them from the model's point of view (perceived from the imitator's point of view), into a metarepresentation permitting their performance from the imitator's point of view" (Whiten \& Byrne, 1988). In developmental psychology, it is common to view imitation as a complicated and rather academic sort of process, only possible once a child has acquired an understanding of other minds and causal processes. The behaviour parsing model (Byrne, 2003) gives a simpler account; in which statistical regularities of repeated skilled actions can be extracted by behaviour parsing, allowing the detection and use of the planning structure from within another person's actions - crucially, without first understanding how their behaviour achieves its ends, or what the precise ends are. By this means, I would argue, it is possible to imitate without mentalising (Byrne, 1999). But parsing another individual's actions nevertheless automatically gives a kind of 'correlational understanding' of the purpose and function of instrumental actions (Byrne, 2006). In this rough-and-ready kind of understanding, purpose becomes simply a result, and in particular a result that causes the individual to cease its previous behaviour - a satisfying result. Similarly, the immediate causal function of actions becomes what they usually do. These, of course, are not purposes and causes at deep explanatory level, but they will probably do for most everyday purposes. Indeed, it may be that we humans manage much of our everyday life without as much mentalising as we often like to imagine. Humans famously tend to ascribe overly complex explanations to their own actions!

I propose that behaviour parsing evolved as an automatic, mechanical and probably unconscious means of interpreting complex behaviour in terms of functions and mechanisms: and hence, in a metaphorical sense, 'seeing' the plans and intentions of others. I suggest that in the same way mechanistic, automatic and fast low-level processes of this sort may well underlie much of everyday human action, even tasks that we conventionally attribute to an understanding of others' intentions or to an understanding of everyday physics. In contrast, true mentalising evolved later and quite independently, as a means of 'talking about it afterwards': for example, allowing teaching of our infants, lying to our competitors, and construing our past behaviour in ways that retrospectively suit us. Mentalisiing, therefore, would be closely linked to the origins of language itself (Figure 8). If these conjectures

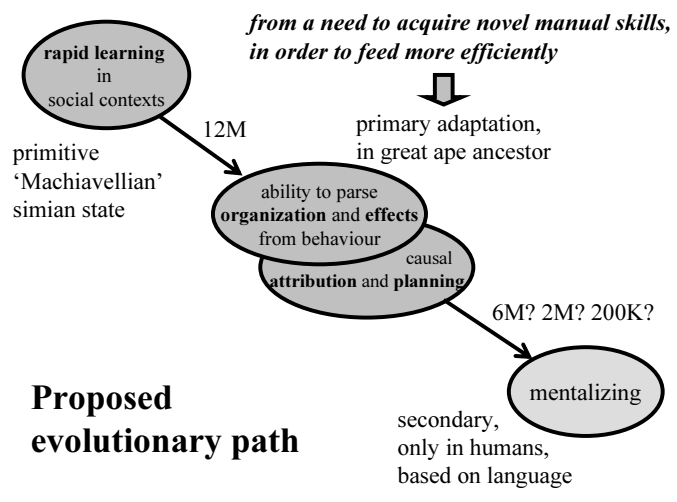

Figure 8. Possible evolutionary history of human mental abilities. On this model, the ability to solve many practical problems often described as 'theory of mind' or causal reasoning' tasks developed before language, in the ancestors all living great apes, as a result of behaviour parsing skills adapted to efficiency in food processing. True mentalizing and deeper understanding of intention and causality developed later, uniquely in humans and closely associated with language. 
are correct, the ability to carry out many richly complex human tasks developed before the ability that we now possess to introspect upon and describe them, and it is these, prementalizing abilities that are increasingly found to be shared with great apes and corvids (Dally, Emery \& Clayton, 2006; Emery \& Clayton, 2004).

Understanding the feeding behaviour of great apes may also give us clues towards the origin of linguistic syntax itself. Great ape calls cannot be modified by experience (Janik \& Slater, 1997): even the dramatic experience of human-rearing in 'ape language' experiments has repeatedly shown that chimpanzees, gorillas and orangutans simply cannot acquire new sounds. They lack the necessary neural control. Moreover, when apes have been trained in aspects of human language syntactical ability is relatively sparse, despite many other highly impressive achievements. But if we turn to the natural abilities of great apes, we find that all genera of great apes acquire feeding skills that are flexible and have syntax-like organisation, with hierarchical structure. Gestural communication in chimpanzees and gorillas is not restricted to a fixed, inborn set of signals but can be extended by learning in a social context (Tanner \& Byrne, 1996, 1999; Tomasello, Call, Nagell, Olguin, \& Carpenter, 1994; Tomasello, George, Kruger, Farrar, \& Evans, 1985), and gestures are used intentionally, sometimes even depicting an intended future action by iconic representation. Perhaps, then, the precursors of linguistic syntax should be sought in primate manual abilities rather than in their vocal skills. Language may have a mosaic origin, resulting from fusion of referential communication, derived from vocal communication, and syntactic skills, derived from manual food processing. It is perhaps an intriguing thought that the highest of all human accomplishments, language, may have originated in the problems that our primate ancestors faced in competing with monkeys over plant foods.

\section{Acknowledgements}

This lecture was given to the 66th Annual Meeting, Kyoto, October $13^{\text {th }}-15^{\text {th }}$ of the Japa- nese Society of Animal Psychology, by kind invitation of Dr Kazuo Fujita.

\section{References}

Boesch, C. (1991). Teaching among wild chimpanzees. Animal Behaviour, 41, 530-532.

Boesch, C., \& Boesch, H. (1983). Optimisation of nut-cracking with natural hammers by wild chimpanzees. Behaviour, 83, 265-286.

Boesch, C., \& Boesch, H. (1993). Different hand postures for pounding nuts with natural hammers by wild chimpanzees. In Hands of primates, ed. H. Preuschoft \& D. J. Chivers, pp. 31-41. New York: Springer-Verlag.

Brothers, L. (1990). The social brain: a project for integrating primate behavior and neurophysiology in a new domain. Concepts in Neuroscience, 1, 27-51.

Byrne, R. W. (1994). The evolution of intelligence. In Behaviour and evolution, ed. P. J. B. Slater \& T. R. Halliday, pp. 223-265. Cambridge: Cambridge University Press.

Byrne, R. W. (1995). The thinking ape: evolutionary origins of intelligence. Oxford: Oxford University Press.

Byrne, R. W. (1998). Imitation: the contributions of priming and program-level copying. In Intersubjective communication and emotion in early ontogeny, ed. S. Braten, pp. 228-244. Cambridge: Cambridge University Press.

Byrne, R. W. (1999). Imitation without intentionality. Using string parsing to copy the organization of behaviour. Animal Cognition, 2, 63-72.

Byrne, R. W. (2002). Imitation of complex novel actions: what does the evidence from animals mean? Advances in the Study of Behavior, 31, 77-105.

Byrne, R. W. (2003). Imitation as behaviour parsing. Philosophical Transactions of the Royal Society of London (B), 358, 529-536.

Byrne, R. W. (2006). Parsing behaviour. A mundane origin for an extraordinary ability? In The roots of human sociality, ed. S. Levinson \& N. Enfield, pp. 478-505. Oxford: Berg.

Byrne, R. W., \& Byrne, J. M. E. (1991). Hand preferences in the skilled gathering tasks of 
RICHARD W BYRNE : Clues to the origin of the human mind from primate observational field data

mountain gorillas (Gorilla g. beringei). Cortex, 27, 521-546.

Byrne, R. W., \& Byrne, J. M. E. (1993). Complex leaf-gathering skills of mountain gorillas (Gorilla g. beringei): Variability and standardization. American Journal of Primatology, 31, 241-261.

Byrne, R. W., \& Corp, N. (2004). Neocortex size predicts deception rate in primates. Proceedings of the Royal Society of London: Biology, 271, 1693-1699.

Byrne, R. W., Corp, N., \& Byrne, J. M. (2001a). Manual dexterity in the gorilla: bimanual and digit role differentiation in a natural task. Animal Cognition, 4, 347-361.

Byrne, R. W., Corp, N., \& Byrne, J. M. E. (2001b). Estimating the complexity of animal behaviour: How mountain gorillas eat thistles. Behaviour, 138, 525-557.

Byrne, R. W., \& Stokes, E. J. (2002). Effects of manual disability on feeding skills in gorillas and chimpanzees: a cognitive analysis. International Journal of Primatology, 23, 539-554.

Byrne, R. W., \& Whiten, A. (1988). Machiavellian Intelligence: Social expertise and the evolution of intellect in monkeys, apes and humans. Oxford: Clarendon Press.

Byrne, R. W., \& Whiten, A. (1990). Tactical deception in primates: the 1990 database. Primate Report, 27, 1-101.

Byrne, R. W., \& Whiten, A. (1992). Cognitive evolution in primates: evidence from tactical deception. Man, 27, 609-627.

Caro, T. M., \& Hauser, M. D. (1992). Is there teaching in non-human animals? Quarterly Review of Biology, 67, 151-174.

Corp, N., \& Byrne, R. W. (2002). The ontogeny of manual skill in wild chimpanzees: Evidence from feeding on the fruit of Saba florida. Behaviour, 139, 137-168.

Dally, J. M., Emery, N. J., \& Clayton, N. S. (2006). Food-caching western scrub-jays keep track of who was watching when. Science, 312 , 1662-1665.

Dunbar, R. I. M. (1998). The social brain hypothesis. Evolutionary Anthropology, 6, 178-190.

Emery, N. J., \& Clayton, N. S. (2004). The mentality of crows: Convergent evolution of intelligence in corvids and apes. Science, 306, 1903-1907.

Galef, B. G. (1988). Imitation in animals: History, definitions, and interpretation of data from the psychological laboratory. In Social Learning: Psychological and biological perspectives, ed. T. Zentall \& B. G. Galef, Jnr., pp. 3-28. Hillsdale, New Jersey: Erlbaum.

Galef, B. G., Manzig, L. A., \& Field, R. M. (1986). Imitation learning in budgerigars: Dawson and Foss (1965) revisited. Behavioural Processes, 13, 191-202.

Goodall, J. (1986). The chimpanzees of Gombe: patterns of behavior. Cambridge, MA: Harvard University Press.

Hare, B., Call, J., Agnetta, B., \& Tomasello, M. (2000). Chimpanzees know what conspecifics do and do not see. Animal Behaviour, 59, 771-785.

Hare, B., Call, J., \& Tomasello, M. (2001). Do chimpanzees know what conspecifics know? Animal Behaviour, 61, 139-151.

Humphrey, N. K. (1976). The social function of intellect. In Growing Points in Ethology, ed. P. P. G. Bateson \& R. A. Hinde, pp. 303-317. Cambridge: Cambridge University Press.

Janik, V. M., \& Slater, P. J. B. (1997). Vocal learning in mammals. Advances in the Study of Behavior, 26, 59-99.

Jolly, A. (1966). Lemur social behaviour and primate intelligence. Science, 153, 501-506.

Kummer, H. (1968). Social organisation of hamadryas baboons. Chicago: University of Chicago Press.

Stokes, E. J., \& Byrne, R. W. (2001). Cognitive capacities for behavioural flexibility in wild chimpanzees (Pan troglodytes):The effect of snare injury on complex manual food processing. Animal Cognition, 4, 11-28.

Stokes, E. J., Quiatt, D., \& Reynolds, V. (1999). Snare injuries to chimpanzees (Pan troglodytes) at 10 study sites in East and West Africa. American Journal of Primatology, 49, 104-105.

Tanner, J. E., \& Byrne, R. W. (1996). Representation of action through iconic gesture in a captive lowland gorilla. Current 
Anthropology, 37, 162-173.

Tanner, J. E., \& Byrne, R. W. (1999). The development of spontaneous gestural communication in a group of zoo-living lowland gorillas. In The mentalities of gorillas and orangutans. Comparative perspectives, ed. S. T. Parker, R. W. Mitchell, \& H. L. Miles, pp. 211-239. Cambridge: Cambridge University Press.

Tomasello, M., \& Call, J. (1997). Primate cognition. New York: Oxford University Press.

Tomasello, M., Call, J., Nagell, C., Olguin, R., \& Carpenter, M. (1994). The learning and use of gestural signals by young chimpanzees: a trans-generational study. Primates, 35, 137154.

Tomasello, M., George, B., Kruger, A., Farrar, J., \& Evans, E. (1985). The development of gestural communication in young chimpanzees. Journal of Human Evolution, 14, 175-186.

Tomasello, M., Kruger, A. C., \& Ratner, H. H. (1993). Cultural learning. Behavioral and
Brain Sciences, 16, 495-552.

Visalberghi, E., \& Fragaszy, D. M. (1990). Do monkeys ape? In "Language" and Intelligence in Monkeys and Apes, ed. S. T. Parker \& K. R. Gibson, pp. 247-273. Cambridge: Cambridge University Press.

Voelkl, B., \& Huber, L. (2000). True imitation in marmosets. Animal Behaviour, 60, 195-202.

Whiten, A., \& Byrne, R. W. (1988). Taking Machiavellian intelligence apart. In Machiavellian Intelligence: Social Expertise and the Evolution of intellect in Monkeys, Apes and Humans, ed. R. W. Byrne \& A. Whiten, pp. 50-65. Oxford: Oxford University Press.

Whiten, A., Custance, D. M., Gomez, J.-C., Teixidor, P., \& Bard, K. A. (1996). Imitative learning of artificial fruit processing in children (Homo sapiens) and chimpanzees (Pan troglodytes). Journal of Comparative Psychology, 110, 3-14.

Zentall, T. R. (2001). Imitation in animals: evidence, function, and mechanisms. Cyber netics \& Systems, 32, 53-96.

(2007. 4.17 受稿, 2007. 5 .15 受理) 